\title{
Social integration: How is it related to self-rated health?
}

\author{
Hejun Kang $^{1^{*}}$, Yvonne L. Michael ${ }^{2}$ \\ ${ }^{1}$ Department of Geography, University of Idaho, Moscow, USA; ${ }^{*}$ Corresponding Author: Hejun@ $@$ uidaho.edu \\ ${ }^{2}$ Department of Epidemiology and Biostatistics, Drexel University, Philadelphia, USA
}

Received 30 November 2012; revised 31 December 2012; accepted 7 January 2013

\begin{abstract}
Social integration has well-established health benefits among older adults in observational studies. However, interventions designed to increase social integration have not improved health suggesting important knowledge gaps on how social integration influences health outcomes. This study developed a new measure of social integration, daily social contact, capturing the interpersonal nature of social integration and mobility of individuals, and providing a direct assessment of individuals' real-time access to companionship and social support. The data used is the 2006-2007 American Time Use Survey (ATUS), which surveyed 25,191 individuals aged 15 years and older $(n=4378$ aged 65 years and older). Generalized ordinal logistic regression analyses revealed positive, but non-parallel relationships between daily social contacts and the ordinal categories of self-rated health among older adults. This study may be used to identify populations that experience social exclusion, such that future research can determine more precisely how to intervene to improve health outcomes.
\end{abstract}

Keywords: Daily Social Contact; Social Integration; Self-Rated Health; Older Adults; Generalized Ordinal Logistic Regression

\section{INTRODUCTION}

Level of integration with society affects how people age. Older adults are considered to be vulnerable to social exclusion [1]. Staying actively integrated with life is critical for people's physical and mental health and health care expenditures [2-4]. Social integration is broadly defined as "concrete involvement of individuals with various aspects of a collectivity" [4] (p. 635). Social integration is often studied through two componentssocial engagement and social networks. Social engage- ment refers to participation in certain activities such as paid employment, clubs, care giving and church activities. Social networks refer to interaction with friends and relatives [5]. Traditional methods for evaluating the association between social integration and the health of seniors typically relies on data obtained from standardized health surveys, which ask about the number of friends and relatives seen routinely and the frequency of participation in activities (such as clubs or religious organizations), but do not provide information about actual social activity participation. Therefore, it is difficult, if not impossible, to use such data to examine seniors' daily level of social contact, not to mention their real access to companionship and social support.

Social integration has well-established health benefits. Conceptually, active engagement in society is identified as one of the three major components of successful aging, including absence of morbidity, and higher cognitive and physical functional capacity [6]. The health benefits of social relationships for older adults are hypothesized to accrue in three primary ways [6]. First, social networks may improve health via social support provided by social networks. Second, an extensive social network increases seniors' likelihood of obtaining a wider variety of resources and seeking instrumental support with aging [7,8]. Third, social networks can help overcome constraints of mobility (as measured as trip generation rates), which are increasingly faced by aging populations. Seniors with limited mobility are likely to report feelings of isolation, less active engagement in society, loss of independence, or danger of being stranded in their own homes [9]. Limited mobility is mainly due to the loss of driving ability [10], along with the fact that public transit is inconvenient, and taxis are too expensive [11]. Thus, when seniors stop driving, they turn to friends and family for ridesharing [12-14].

Despite strong evidence from observational studies, interventions designed to increase social integration have not improved health outcomes, suggesting important gaps in our knowledge of how social integration influences health outcomes. Measuring social integration is an important first step to assure that all socially excluded 
people are identified or located [15]. The previous studies on the measurement of social integration can be broadly classified into two categories, as discussed below.

The first category of studies measures social integration collectively by its two components-social network and social engagement. Social networks are measured as the number of social ties that include contact and the proximity of four groups of ties: children, relatives, friends, and confidants [16,17]. Social activities take many forms, among which interpersonal relations and productive activity are most concerned [6]. Interpersonal relations involve contacts with others, information exchange, emotional support, and direct assistance. Mendes de Leon et al. [5] classified activities into 11 types (i.e., visits to theaters/sporting events, shopping, gardening, meal preparation, card/game playing, day or overnight trips, paid community work, unpaid community work, church, groups and paid employment). Then respondents are asked how often they participated in each type $(0$, never; 1, sometimes; 2, often). A summary measure of all reported frequencies was then used to represent social engagement. One limitation of this approach is there is no consensus on the spectrum of social activities across different studies and surveys, which might be attributable to the lack of knowledge about the "latent" context of social activities [5].

The second group of prior studies explores other measures of social integration, from a transportation perspective, which include accessibility (i.e., access to transportation services) and mobility (i.e., trip frequency) $[1,15,18]$. One hypothesis in this line of research is that social excluded population groups (i.e., the elderly, single parents and those with lower incomes) are likely to be transportation disadvantaged; therefore improving transportation conditions could help reduce social exclusion. However, empirical studies showed that mobility of social excluded population groups is not significantly different from the general population $[15,19]$, nor is accessibility completely coincident with social exclusion [18]. For instance, Ronda et al. [19] reported single parents actually made even more trips than singles without children. Therefore, neither of the above two transportation indices is a perfect indicator of social exclusion.

This study developed a new measure of social integration consolidating measures employed in the above two groups of studies in order to capture the multidimensional nature of social integration. A person's social integration was measured as the number of out-ofhome non-working, non-sleeping activities and trips made in the company of others in his/her social circle (i.e., family or friends), also called joint, out-of-home activities/trips. This new measure reflected the interpersonal nature of social activities, and evaluated the transportation mobility of individuals, which collectively pro- vided a direct assessment of individuals' real-time access to companionship and social support [20,21]. Additionally, using the number of joint, out-of-home activities and trips to measure social integration helped address the challenge of delineating the spectrum of social activities, which is a common issue in social integration studies [5].

Joint, out-of-home activities/trips are used inter-changeably with the daily social contact throughout the paper. Using the new measure of social integration, two hypotheses were tested. First, the daily social contacts decreased as age increases. Second, the self-rated health of older adults was positively associated with the level of daily social contacts.

\section{METHODS}

\subsection{Study Sample}

Data were obtained from the 2006-2007 American Time-Use Survey (ATUS), which records individuals' time diaries and heath data from nationally representative panel data of adults aged 15 years and over (a total of 25,191 persons). The 2006-2007 ATUS included 4378 adults aged 65 years and older. The ATUS sample was drawn from the Current Population Survey (CPS). The sample frame was the civilian, noninstitutional population residing in occupied households in the United States; respondents were selected using a stratified sampling process based on the race/ethnicity, the presence and age of children, and the number of adults. The CPS was subsampled to obtain the ATUS sample, distributed across the States approximately equal to the proportion of the national population each one represents.

ATUS collected 24-hour recall diaries from its participants, achieving a full account of their daily activities/ trips on the day immediately preceding the interview. ATUS respondents reported all activities that they have participated within 24 hours and the shortest unit of time for any reported activity is 5 minutes (see Table 1). For each activity, the following information was collected: 1) what type of each activity the respondent was doing; 2) with whom the respondent was during each activity; 3) where each activity occurred; 4) the times at which each activity began and ended.

\subsection{Measures}

Social integration. Social integration was measured by the daily social contact, which counted the number of all out-of-home non-work, non-sleep activities and travel in the company of family and/or friend per day for each person. The daily social contact was calculated by: 1) eliminating any activities conducted alone, which did not involve social interpersonal interaction or contact; 2) excluding all activities undertaken at-home, which did not require any transportation; 3) excluding work, educa- 
Table 1. Classification of non-work, non-sleep activities in the ATUS.

\begin{tabular}{|c|c|}
\hline Categories & Description \\
\hline Socializing & Socializing, relaxing, and leisure \\
\hline Sports & Sports, exercise, and recreation \\
\hline Religious & Religious and spiritual activities \\
\hline Volunteer & Volunteer activities \\
\hline Personal care & $\begin{array}{l}\text { Health-related self-care, } \\
\text { excluding sleep and grooming }\end{array}$ \\
\hline $\begin{array}{l}\text { Household } \\
\text { activities }\end{array}$ & $\begin{array}{l}\text { Food preparation, laundry, } \\
\text { cleaning, repair, decoration }\end{array}$ \\
\hline Caring people & $\begin{array}{l}\text { Playing, providing/obtaining medical care, pick } \\
\text { up or drop off, attending children's events }\end{array}$ \\
\hline $\begin{array}{l}\text { Consumer } \\
\text { purchases }\end{array}$ & Grocery shopping, gas, and other shopping \\
\hline $\begin{array}{l}\text { Professional and } \\
\text { personal care } \\
\text { services }\end{array}$ & $\begin{array}{l}\text { Childcare, financial, legal, medical, } \\
\text { and care-related services }\end{array}$ \\
\hline $\begin{array}{l}\text { Household } \\
\text { services }\end{array}$ & $\begin{array}{c}\text { Household services not done by self, including home } \\
\text { maintenance, repair, decoration, construction, } \\
\text { pet, lawn, vehicle services }\end{array}$ \\
\hline Food & Eating and drinking \\
\hline Travel & $\begin{array}{l}\text { Various modes of transportation including driver, } \\
\text { passenger, walking, public transit, bicycle, } \\
\text { boat, ferry, taxi, airplane }\end{array}$ \\
\hline
\end{tabular}

tion or sleep activities, as the social contact data were not collected for these activities; and 4) counting the total number of all the qualified activities that are kept from steps of 1-3.

Self-rated health. Participants were asked to rate their health in the Eating and Health (EH) module of ATUS a 5-point scale (1-poor, 2-fair, 3-good, 4-very good, 5excellent). Self-rated health has been a reliable and valid measure of overall health [22-24]. Among a total of 25,191 respondents, $4.4 \%$ rated their health as poor, $12.4 \%$ as fair, $29.4 \%$ as good, $33.5 \%$ as very good, and $20.3 \%$ as excellent. The first two categories of self-rated health, fair and poor health, were combined in the generalized ordered logistic regression analysis resulting in four categories due to few respondents who rated their health as poor.

Covariates. Socio demographic characteristics of seniors include age, gender $(0=$ male, $1=$ female $)$, region of residence $(1=$ living in metropolitan area, $0=$ not living in metropolitan area), house tenure $(1=$ own, $0=$ rent $)$, living arrangement (living alone, living with a spouse, living with others), marital status, annual household income (ordinal, 1 if $<\$ 20,000$, and 5 if $\geq \$ 75,000$ ), citizenship $(1=$ foreign born, $0=$ native born $)$, employment status $(1=$ employed, $0=$ not employed $)$, and body mass index $\left(\mathrm{kg} / \mathrm{m}^{2}\right)$ (underweight, normal weight, over- weight and obese).

The selection of the variables in the empirical analysis was informed by findings of prior studies on predictors of self-rated health (e.g., [5,22,25-27], and also constrained by data availability.

\section{RESULTS}

\subsection{Sample Characteristics}

Table 2 displays a description of the study sample by self-rated health. For all participants, the average age was 55.98 ( $\mathrm{SD}=17.76$ ). Approximately $57 \%$ were female, $63 \%$ had a job, either full-time or part-time, $25 \%$ lived in a rented place, and $82 \%$ lived in metropolitan area. People who reported their health status as very good or excellent, tended to be male, younger, employed and richer, more likely to own a house and living in metropolitan area. Compared to people living alone or with others, those living with their spouses were more likely to rate their health better. Non-native citizens rated their health much lower than native citizens did. People with higher levels of self-rated health status also reported a lower BMI and greater daily social contact. Specifically, the total number of out-of-home non-work, non-sleep activaity and travels with friends and/or family increased from 1.22 to 3.03 per day on average with self-reported health varying from very poor to excellent.

Table 3 provides evidence that as age increased, social integration (daily social contact) decreased dramatically. In particular, seniors showed lowest social contact among all the age groups, while the youngest $(<20)$ being the highest. On average, people aged 65 years and over had 1.65 daily social contacts with others, 1.81 lower than people 15 - 19 years old. Only the 20 - 34 and 35 - 49 year old age groups were not statistically different, but the daily social contact of the former group was higher than the latter group.

Figure 1 shows the cross-sectional association between daily social contact and self-rated health among older adults (4378 respondents). It was observed that seniors were more likely to report a higher level of health when they participated in more joint, out-of-home activities/ travel with friends and/or family. The association between health and social integration was linear except that seniors who reported excellent health status had slightly lower social integration compared to those with very good health status, but still higher than the other three groups-poor, fair and good. This could be attributable to other important factors besides the daily social contact, such as income, and employment status, which were addressed as covariates in the regression model as described below.

This study further evaluated the association between self-rated health and the level of social integration, with 
Table 2. Sample characteristics for each self-rated health status. ${ }^{* * *} p<0.001$.

\begin{tabular}{|c|c|c|c|c|c|c|c|}
\hline \multirow{2}{*}{$\begin{array}{c}\text { Characteristics } \\
\text { Number of participants }\end{array}$} & \multirow[t]{2}{*}{ Total $(N)$} & \multicolumn{5}{|c|}{ Self-rated health $\%$ or mean (SD) } & \multirow[b]{2}{*}{ Comparison tes } \\
\hline & & $\begin{array}{c}\text { Poor } \\
(n=1108)\end{array}$ & $\begin{array}{c}\text { Fair } \\
(n=3125)\end{array}$ & $\begin{array}{c}\text { Good } \\
(n=7417)\end{array}$ & $\begin{array}{l}\text { Very good } \\
(n=8447)\end{array}$ & $\begin{array}{c}\text { Excellent } \\
(n=5094)\end{array}$ & \\
\hline \multicolumn{8}{|l|}{ Socioeconomic factors } \\
\hline Sex & & & & & & & $X^{2}=25.6^{* * *}$ \\
\hline Male & 10,814 & 4.0 & 11.8 & 29.1 & 33.7 & 21.4 & \\
\hline Female & 14,377 & 4.7 & 12.9 & 29.7 & 33.4 & 19.3 & \\
\hline Age group (years) & & & & & & & $X^{2}=1643.8^{* * *}$ \\
\hline$<20$ & 1875 & 0.5 & 6.0 & 30.3 & 39.8 & 23.3 & \\
\hline $20-34$ & 5260 & 1.1 & 8.3 & 30.5 & 36.9 & 23.2 & \\
\hline $35-49$ & 8118 & 2.6 & 9.2 & 28.0 & 37.5 & 22.6 & \\
\hline $50-64$ & 5560 & 7.2 & 15.5 & 28.2 & 30.5 & 18.6 & \\
\hline $65+$ & 4378 & 9.8 & 22.0 & 32.0 & 23.2 & 13.0 & \\
\hline Living arrangement & & & & & & & $X^{2}=473.2^{* * *}$ \\
\hline Alone & 6022 & 7.7 & 16.7 & 29.5 & 28.4 & 17.6 & \\
\hline With spouse & 13,335 & 3.1 & 10.4 & 28.5 & 36.2 & 21.9 & \\
\hline With others & 5834 & 4.0 & 12.5 & 31.6 & 32.7 & 19.1 & \\
\hline Family income & & & & & & & $X^{2}=2808.7^{* * *}$ \\
\hline Refuse or do not know & 3338 & 5.2 & 15.2 & 30.1 & 30.0 & 19.6 & \\
\hline$<\$ 20,000$ & 4085 & 13.4 & 22.6 & 31.8 & 20.3 & 11.9 & \\
\hline$\$ 20,000-\$ 40,000$ & 5350 & 4.2 & 15.4 & 34.4 & 29.9 & 16.1 & \\
\hline$\$ 40,000-\$ 60,000$ & 3886 & 2.2 & 10.0 & 31.3 & 36.6 & 20.0 & \\
\hline$\$ 60,000-\$ 75,000$ & 2299 & 1.6 & 7.4 & 27.6 & 41.4 & 22.1 & \\
\hline$\$ 75,000+$ & 6233 & 0.7 & 5.0 & 22.8 & 42.5 & 29.0 & \\
\hline House tenure & & & & & & & $X^{2}=396.5^{* * *}$ \\
\hline Rent & 6363 & 6.9 & 16.7 & 31.8 & 27.5 & 17.1 & \\
\hline Own & 18,828 & 3.6 & 10.9 & 28.6 & 35.6 & 21.3 & \\
\hline Employment status & & & & & & & $X^{2}=2028.5^{* * *}$ \\
\hline Employed & 15,756 & 1.1 & 8.3 & 29.4 & 38.3 & 22.9 & \\
\hline Not employed & 9435 & 9.9 & 19.3 & 29.5 & 25.5 & 15.8 & \\
\hline Citizenship & & & & & & & $X^{2}=200.7^{* * *}$ \\
\hline Native born & 22,006 & 4.5 & 11.8 & 28.5 & 34.9 & 20.3 & \\
\hline Foreign born & 3185 & 3.9 & 16.5 & 35.9 & 24.1 & 19.6 & \\
\hline Body mass index & & $28.89(9.55)$ & $27.83(9.77)$ & $26.47(8.92)$ & $25.23(7.37)$ & $22.33(8.60)$ & $\mathrm{F}=305.3^{* * *}$ \\
\hline \multicolumn{8}{|l|}{ Region of residence } \\
\hline Non-metropolitan area & 4579 & 5.8 & 14.6 & 30.6 & 31.8 & 17.2 & $X^{2}=79.8^{* * *}$ \\
\hline Metropolitan area & 20,612 & 4.1 & 11.9 & 29.2 & 33.9 & 20.9 & \\
\hline \multicolumn{8}{|l|}{ Social integration measure } \\
\hline Daily social contact & & $1.22(2.57)$ & $1.94(3.18)$ & $2.55(3.70)$ & $3.01(3.95)$ & $3.03(4.02)$ & $\mathrm{F}=101.7^{* * *}$ \\
\hline
\end{tabular}


Table 3. Pairwise multiple comparison of the social contact by age in one-way ANOVA.

\begin{tabular}{|c|c|c|c|c|c|}
\hline \multirow{2}{*}{ (I) Age category } & \multirow{2}{*}{$\begin{array}{c}\text { Daily social contact } \\
\text { Mean (Std.) }\end{array}$} & \multirow{2}{*}{ (J) Age category } & \multirow{2}{*}{$\begin{array}{c}\text { Mean } \\
\text { difference (I - J) }\end{array}$} & \multicolumn{2}{|c|}{$95 \%$ Confidence interval } \\
\hline & & & & Upper bound & Lower bound \\
\hline \multirow[t]{4}{*}{$<20$} & $3.47(4.09)$ & $20-34$ & $0.332^{* *}(0.100)$ & 0.03 & 0.64 \\
\hline & & $35-49$ & $0.405^{* * *}(0.096)$ & 0.11 & 0.70 \\
\hline & & $50-64$ & $1.291^{* * *}(0.100)$ & 1.00 & 1.59 \\
\hline & & $65+$ & $1.811^{* * *}(0.103)$ & 1.52 & 2.10 \\
\hline \multirow[t]{4}{*}{$20-34$} & $3.13(4.01)$ & $<20$ & $-0.332^{* *}(0.100)$ & -0.64 & -0.03 \\
\hline & & $35-49$ & $0.073(0.066)$ & -0.13 & 0.27 \\
\hline & & $50-64$ & $0.959^{* * *}(0.072)$ & 0.76 & 1.16 \\
\hline & & $65+$ & $1.479^{* * *}(0.076)$ & 1.28 & 1.67 \\
\hline \multirow[t]{4}{*}{$35-49$} & $3.06(4.09)$ & $<20$ & $-0.405^{* * *}(0.096)$ & -0.70 & -0.11 \\
\hline & & $20-34$ & $-0.073(0.066)$ & -0.27 & 0.13 \\
\hline & & $50-64$ & $0.886^{* * *}(0.065)$ & 0.71 & 1.07 \\
\hline & & $65+$ & $1.406^{* * *}(0.070)$ & 1.23 & 1.58 \\
\hline \multirow[t]{4}{*}{$50-64$} & $2.17(3.41)$ & $<20$ & $-1.291^{* * *}(0.100)$ & -1.59 & -1.00 \\
\hline & & $20-34$ & $-0.959^{* * *}(0.072)$ & -1.16 & -0.76 \\
\hline & & $35-49$ & $-0.886^{* * *}(0.065)$ & -1.07 & -0.71 \\
\hline & & $65+$ & $0.520^{* * *}(0.075)$ & 0.35 & 0.70 \\
\hline \multirow[t]{4}{*}{$65+$} & $1.65(2.81)$ & $<20$ & $-1.811^{* * *}(0.103)$ & -2.10 & -1.52 \\
\hline & & $20-34$ & $-1.479^{* * *}(0.076)$ & -1.67 & -1.28 \\
\hline & & $35-49$ & $-1.406^{* * *}(0.070)$ & -1.58 & -1.23 \\
\hline & & $50-64$ & $-0.520^{* * *}(0.075)$ & -0.70 & -0.35 \\
\hline
\end{tabular}

Notes: Standard errors are in parentheses. ${ }^{* * *},{ }^{* *},{ }^{*}$ denote statistical significance at the 1,5 , and 10 percent levels.

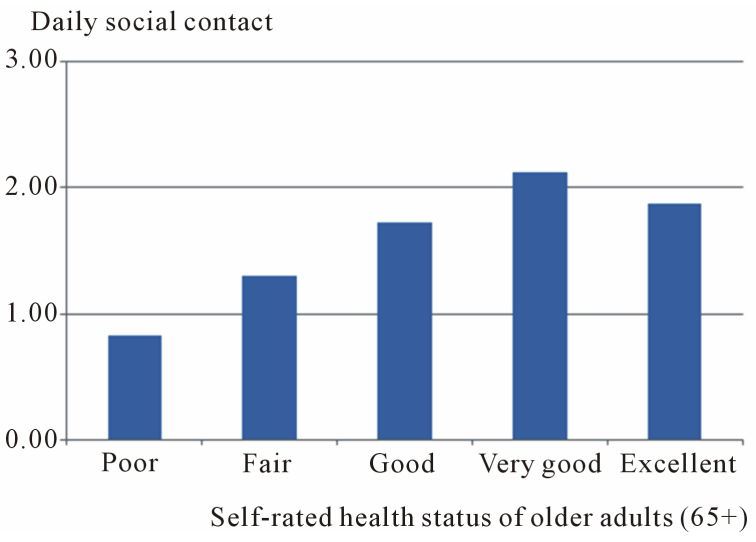

Figure 1. Faily social contact and the self-rated health of older adults $(65+)$.

a focus on seniors ( 65 years and older). Table 4 provides a description and statistics for each variable used in the generalized ordered logistic regression model. Compared to the general population $(15+)$, the proportion of older adults who reported their health status as poor/fair, or good is much higher $(31.88 \%$, and $31.98 \%)$ and the proportion of reporting very good or excellent is significantly lower $(23.16 \%$, and $12.97 \%)$. For all older adults, $81.2 \%$ of them own a house, $77 \%$ live in metropolitans, and $53.7 \%$ live alone. $16 \%$ of older adults are still working, but around $30 \%$ of them having household income lower than $\$ 20,000,63 \%$ are female, $8 \%$ are Hispanic, and $7 \%$ of them were born outside the US.

\subsection{Regression Models of Self-Rated Health}

Before estimating gologit2, ordinary logistic analysis was estimated, and the proportional odds assumption was tested. Not surprisingly, the null hypothesis which assumes the relationships between the independent variables and each category of the outcome variable be same, was rejected $(p<0.01)$.Thus, gologit 2 was estimated and only the best model was reported and discussed in this study. 
Table 4. Definitions and descriptive statistics of variables.

\begin{tabular}{|c|c|c|c|}
\hline Variables & Definition & $\begin{array}{c}\text { Categorical } \\
\text { variables (percent) }\end{array}$ & $\begin{array}{c}\text { Continuous } \\
\text { variables (mean) }\end{array}$ \\
\hline \multicolumn{4}{|l|}{ Dependent Variables } \\
\hline \multirow[t]{4}{*}{ Self-rated health status } & 1—Poor/Fair & 31.88 & \\
\hline & 2 - Good & 31.98 & \\
\hline & 3 -Very good & 23.16 & \\
\hline & 4-Excellent & 12.97 & \\
\hline \multicolumn{4}{|l|}{ Independent Variables } \\
\hline \multicolumn{4}{|l|}{ Household attributes } \\
\hline \multirow{5}{*}{ Family income } & Income $<20 \mathrm{~K}$ & 29.81 & \\
\hline & $20 \leq$ Income $<40 \mathrm{~K}$ & 47.81 & \\
\hline & $40 \leq$ Income $<60 \mathrm{~K}$ & 10.07 & \\
\hline & $60 \leq$ Income $<75 \mathrm{~K}$ & 4.29 & \\
\hline & $75 \mathrm{~K} \leq$ Income & 8.02 & \\
\hline House tenure & Owning a house & 81.16 & \\
\hline Metropolitan & 1 if living in metropolitan area & 77.04 & \\
\hline \multirow[t]{4}{*}{ Living region } & Northeast region & 19.3 & \\
\hline & Midwest region & 24.0 & \\
\hline & West region & 19.0 & \\
\hline & South region & 37.8 & \\
\hline \multirow[t]{3}{*}{ Living arrangement } & Living alone & 53.70 & \\
\hline & With a spouse & 37.32 & \\
\hline & With others & 8.98 & \\
\hline \multicolumn{4}{|l|}{ Individual attributes } \\
\hline Age & Age in years & & 74.04 \\
\hline Female & 1 if female & 63.36 & \\
\hline Citizenship & 1 if foreign born & 7.41 & \\
\hline Hispanic & 1 if Hispanic & 8.2 & \\
\hline Employment & 1 if employed & 16.06 & \\
\hline Underweight & $\mathrm{BMI}<18.5$ & 5.8 & \\
\hline Overweight & $25 \leq \mathrm{BMI} \leq 29.9$ & 37.7 & \\
\hline Obese & $30 \leq \mathrm{BMI}$ & 22.7 & \\
\hline Normal weight & $18.5 \leq \mathrm{BMI} \leq 24.9$ & 33.7 & \\
\hline \multicolumn{4}{|l|}{ Social integration } \\
\hline Daily social contact & $\begin{array}{l}\text { The number of non-work, non-sleep, out-of-home activities } \\
\text { and trips in accompany of family and/or friends }\end{array}$ & & 1.65 \\
\hline
\end{tabular}

Table 5 describes the results of the generalized ordinal logistic regression model, which estimated the self-rated health status of seniors $(65+)$. In this model, explanatory variables were characterized into three groups: household attributes (family income, house tenure, living region, and living arrangement), individual attributes (age, 
Table 5. Generalized ordinal logistic regression model results of the self-rated health status of old adults $(65+)$.

\begin{tabular}{|c|c|c|c|c|c|}
\hline & Model & & & & Reference category \\
\hline $\begin{array}{l}\text { Self-rated health (1: Poor + Fair; 2: } \\
\text { Good; 3: Very good; 4: Excellent) }\end{array}$ & $\beta$ & $\mathrm{SE}$ & $p$ & $\mathrm{OR}^{\mathrm{a}}$ & \\
\hline \multicolumn{6}{|l|}{$2-4$ vs. 1} \\
\hline Constant & 9.224 & 1.645 & 0.000 & & \\
\hline Daily social contact ${ }^{\mathrm{b}}$ & 0.089 & 0.014 & 0.000 & 1.093 & \\
\hline \multicolumn{6}{|l|}{ Individual factors } \\
\hline Log age & -4.350 & 0.876 & 0.000 & 0.013 & \\
\hline Female & 0.178 & 0.075 & 0.017 & 1.195 & Male \\
\hline Underweight & 0.444 & 0.168 & 0.008 & 1.559 & Normal weight $(18.5 \leq \mathrm{BMI} \leq 24.9)$ \\
\hline Overweight $(25 \leq \mathrm{BMI} \leq 29.9)$ & -0.311 & 0.067 & 0.000 & 0.733 & \\
\hline Obese $(30 \leq \mathrm{BMI})$ & -0.859 & 0.080 & 0.000 & 0.424 & \\
\hline Hispanic & -0.721 & 0.112 & 0.000 & 0.486 & Non-hispanic \\
\hline \multicolumn{6}{|l|}{ Household factors } \\
\hline Living alone & 0.186 & 0.068 & 0.006 & 1.204 & \\
\hline Living with other people & -0.321 & 0.110 & 0.003 & 0.726 & Living with a spouse \\
\hline Living at an owned place & 0.401 & 0.079 & 0.000 & 1.493 & Living in a rented place \\
\hline$\$ 40,000$ to $\$ 59,999$ & -0.606 & 0.134 & 0.000 & 0.546 & \\
\hline$\$ 60,000$ to $\$ 74,999$ & -0.470 & 0.165 & 0.004 & 0.625 & \\
\hline Northeast & 0.220 & 0.079 & 0.006 & 1.246 & South \\
\hline Midwest & 0.399 & 0.089 & 0.000 & 1.490 & \\
\hline West & 0.186 & 0.080 & 0.020 & 1.205 & \\
\hline $\begin{array}{l}\text { Metropolitan } \\
3 \text { - } 4 \text { vs. } 1 \text { - } 2\end{array}$ & \multicolumn{4}{|c|}{$3-4$ vs. $1-2$} & Non-metropolitan area \\
\hline Constant & 7.767 & 1.642 & 0.000 & & \\
\hline \multicolumn{6}{|l|}{ Social integration } \\
\hline Daily social contact & 0.062 & 0.012 & 0.000 & 1.064 & \\
\hline \multicolumn{6}{|l|}{ Individual factors } \\
\hline Female & 0.079 & 0.072 & 0.277 & 1.082 & \\
\hline Employment & 0.708 & 0.091 & 0.000 & 2.030 & \\
\hline Underweight (BMI < 18.5) & 0.438 & 0.140 & 0.002 & 1.550 & \\
\hline \multicolumn{6}{|l|}{ Household factors } \\
\hline Less than $\$ 20,000$ & -1.245 & 0.133 & 0.000 & 0.288 & \\
\hline$\$ 20,000$ to $\$ 40,000$ & -0.841 & 0.119 & 0.000 & 0.431 & \\
\hline
\end{tabular}




\begin{tabular}{|c|c|c|c|c|}
\hline Midwest & 0.209 & 0.084 & 0.013 & 1.232 \\
\hline \multicolumn{5}{|l|}{4 vs. $1-3$} \\
\hline Constant & 6.305 & 1.642 & 0.000 & \\
\hline \multicolumn{5}{|l|}{ Social integration } \\
\hline Daily social contact & 0.026 & 0.016 & 0.097 & 1.026 \\
\hline \multicolumn{5}{|l|}{ Individual factors } \\
\hline Female & -0.216 & 0.097 & 0.026 & 0.806 \\
\hline Employment & 0.677 & 0.113 & 0.000 & 1.968 \\
\hline Underweight $(\mathrm{BMI}<18.5)$ & 1.424 & 0.152 & 0.000 & 4.154 \\
\hline \multicolumn{5}{|l|}{ Household factors } \\
\hline Less than $\$ 20,000$ & -0.997 & 0.160 & 0.000 & 0.369 \\
\hline$\$ 20,000$ to $\$ 40,000$ & -0.574 & 0.134 & 0.000 & 0.564 \\
\hline Midwest & 0.095 & 0.114 & 0.408 & 1.099 \\
\hline \multicolumn{5}{|l|}{ Summary statistics } \\
\hline Sample size & 4378 & & & \\
\hline Log-likelihood & -5404.9 & & & \\
\hline Chi-square test ( $p$ value) & 0 & & & \\
\hline Pseudo $\mathrm{R}^{2}$ & 0.074 & & & \\
\hline
\end{tabular}

${ }^{\mathrm{a}}$ In generalized ordinal logistic regression, an increase of one unit in the predictor results in the odds of an outcome changed by exp $(\beta)$, holding all other vari-

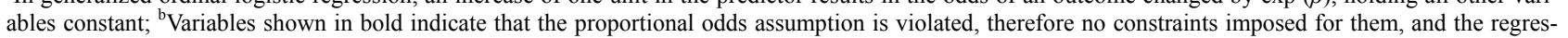
sion coefficient is allowed to change across all ordered responses. All other variables which meet the assumption are not included in the lower two panels of the table.

gender, race/ethnicity, employment status, body mass index) and level of social integration, measured as the daily number of social contacts with family or friends.

In the model output, variables shown in bold, including female, employment, underweight, income less than $\$ 20,000$ and between $\$ 20,000$ and $\$ 40,000$, daily social contact, and Midwest region, did not meet the proportional odds assumption. These variables were included in all three panels of Table 5 (2 - 4 vs. 1; 3 - 4 vs. 1 - 2; and 4 vs. 1 - 3 with 1 being poor/fair and 4 being excellent), and their regression effects varied across each ordinal response. All other variables that already met the assumption were "constrained" so that the effects would remain same in all three panels and, therefore, were only included in the first panel of Table 5 (2 - 4 vs. 1).

In the generalized ordinal logistic regression model, a positive coefficient suggests a higher self-rated health given all other covariates being equal. The odds ratio (OR) refers to the odds of reporting a higher self-rated health given a one-unit increase in the independent variables.

The number of daily social contact was positively associated with better self-rated health of older adults. For each one-unit increase in the number of daily social contact with friends or family, for example, an increase from 1 contact to 2 contacts, the odds of good, very good, and excellent health versus poor/fair was1.09. The odds associated with a one-unit increase in social contact varied by health status comparison: 1.06 for the combination of very good and excellent versus good and poor/fair, and 1.03 for excellent versus the combination of all other self-rated health categories (poor/fair, good, and very good).

Among older adults, increasing age was consistently associated with worse health. The negative effect on health $(\mathrm{OR}=0.013)$ was constrained in this model so the effect remained same across all the three health comparison panels.

Gender was more complicated. Results indicated that females were more likely to report better health versus poor/fair than males (OR = 1.2); but they were less likely to report excellent levels of health compared to worse health $(\mathrm{OR}=0.81)$, i.e., females tended to be less at the extremes of health than males. Additionally, Hispanic older adults were less likely to report higher self-rated health $(\mathrm{OR}=0.5)$ compared to non-Hispanic older adults. 
We found obese and overweight people were less likely to report higher self-rated health compared to normal weight people. However, underweight people were more likely to report better health, and the odds of reporting excellent health versus worse health by underweight people was four times the odds by normal weight people $(\mathrm{OR}=4.15)$.

Among older adults, people with better socio-economic status (SES), e.g., higher income, being employed and owning a house tend to report higher self-rated health in this study. People who owned a house were more likely to report better health $(\mathrm{OR}=1.493)$ than those living at a rented place. For older adults who were employed, the odds of reporting better health versus worse health was much higher than the retired people $(\mathrm{OR}=2.721,2.03$ and 1.96 for all three panels). Our results also indicated that older adults living in metropolitans were more likely to have a better health $(\mathrm{OR}=$ 1.19), relative to those living in non-metropolitan area. Compared with those living in South, older adults living in Northeast, Midwest and West were more likely to report better health. Additionally, compared to those living with a spouse, seniors who live alone were more likely to report better health $(\mathrm{OR}=1.20)$, but those living with non-spouse people were less likely to do so $(\mathrm{OR}=0.726)$.

\section{CONCLUSIONS AND DISCUSSIONS}

Our study developed a new measure of social integration, which captured the interpersonal nature of social activities and incorporated mobility of individuals, provided a direct assessment of individuals' real-time access to companionship and social support.

The number of daily social contact was positively associated with the self-rated health of older adults, suggesting that seniors in active daily contact with friends and/or family were likely to report better health. This finding is consistent to prior studies which indicates that social integration can help obtain more social support and resources through networks [7,8], and overcome constraints of mobility [9]. Our results also suggest that health benefits could be achieved from promoting social contacts, therefore guiding the development of target interventions to enhance health. Recent studies have identified that urban design and land use planning, along with other intervention factors, can improve social contacts. For instance, Fan and Khattak [28] found that easier access to green parks at residence are associated with higher chances of participating out-of-home recreation with family members.

The investigation of health benefits of social integration for seniors is especially meaningful for the following reasons. First, compared to people in the work force, most seniors have a more flexible schedule, which is relatively easier for them to schedule activities with peo- ple due to much less constraints [29-32]. This, however, is inconsistent to the fact that seniors showed lower social contacts as observed. Second, studies have shown that seniors rely more on social contact than younger age groups to counteract mobility loss [33], or to feel more satisfied/needed e.g., providing childcare [34].

Besides social integration, our findings show that previously reported factors for predicting self-rated health also are of importance in our study. It has been reported that better socioeconomic indicators, e.g., higher income, being employed, owning a house, and higher education level, have proved to be positively related to better perceived health [23,35-37]. This could be partly because these socio-economic advantages facilitate access to and use of health care and preventive services [22].

The use of generalized ordinal logistic regression, compared to the commonly used ordered logistic regression, allows the effects of some explanatory variables to vary across ordinal responses of self-rated health, which therefore provides more insights into its predictors. For instance, our results indicated that females are less likely to report extremely low or high health status than males. This is partially supported the study by Shooshtari and colleagues [38] which reported that men were more likely than women to rate their health as either fair or poor.

Very few studies have examined the association of living region of respondents (metropolitan vs. non-metropolitan) in determining health status. Our results suggest that those living in metropolitan area were more likely to have better health, relative to those in non-metropolitan area. This is consistent with the so-called "urban health advantage", which attributes the health benefits of city living to: 1) the availability of higher levels of social support and greater social cohesion in urban than nonurban areas; 2) more access to the necessities of life; 3 ) a physical environment that is conductive to health, e.g., walking; and 4) more resources for health [26]. Additionally, seniors living alone were more likely to have better health status than those living with a spouse, or those living with other non-spouse people. This was reported by Michael and colleagues [25], who found that women living alone are neither socially isolated nor at increased risk for decline in functional health status. In fact, these women actually were far better on measures of psychological function than women living with a spouse. This could be a result of a higher level of social contact with friends and relatives, which would significantly increase the self-rated health of older adults living alone.

It has been well documented that individuals' health condition deteriorates markedly with age [22]. Our study also suggested that the older the age, the lower level of health was reported by older adults. Additionally, Hispanics were more likely to report poor health, and the negative effect has been reported in prior studies [22,35]. 
We found a lower self-rated health for obesity and overweight compared with normal weight, in line with previous studies $[37,39,40]$.

There are several limitations of this study. First, this study used a one-day diary, which may not reflect people's real social contact due to the day-to-day dynamics [41]. However, a multi-day dairy is more difficult to collect due to high response burden and increased costs. Second, the data only allowed evaluation of the crosssectional effect of daily social contact on the self-rated health status of seniors. Future research should address the alternative hypothesis that seniors with better health might be more likely to contact with friends or family. Third, virtual interactions among seniors, such as onlinechatting or making phone calls for emotional support or exchange of information, should be taken into account when data is available. Furthermore, any differential effects of disaggregated social activities on self-rated health could also be investigated. For instance, will having dinner with friends be more beneficial to health than taking care of own children? Finally, daily social contact should be tested for other socially vulnerable groups such as single parents, and people from lower household incomes, before any generalization of present findings regarding social integration and health.

Overall, this study provides new insights into social integration by employing daily social contact as a measurement of social integration, and evaluating its implications on self-rated health. This approach can be used to identify populations that experience social exclusion, such that future research can determine more precisely how to intervene to improve health outcomes.

\section{REFERENCES}

[1] Social Exclusion Unit (2003) Making the connections: Final report on transport and social exclusion. Office of the Deputy Prime Minister, London.

[2] Bassuk, S.S., Glass, T.A. and Berkman, L.F. (1999) Social disengagement and incident cognitive decline in community-dwelling elderly persons. Annals of Internal Medicine, 131, 65-173.

[3] Koenig, H.G., Hays, J.C. and Larson, D.B. (1999) Does religious attendance prolong survival? A six-year followup study of 3968 older adults. Journal of Gerontology A, 54, 370-376. doi:10.1093/gerona/54.7.M370

[4] Muscick, M.A., Herzog, A.R. and House, J.S. (1999) Volunteering and mortality among older adults: Findings from a national sample. The Journals of Gerontology: Series $B$, 54, 173-180. doi:10.1093/geronb/54B.3.S173

[5] Mendes de Leon, C.F., Glass, T.A. and Berkman, L.F. (2003) Social engagement and disability in a community population of older adults. American Journal of Epidemiology, 157, 633-642. doi:10.1093/aje/kwg028

[6] Rowe, J.W. and Kahn, R.L. (1997) Successful aging. The
Gerontologist, 37, 433-440. doi:10.1093/geront/37.4.433

[7] Agneessens, F.H., Waege, H. and Lievens, J. (2006) Diversity in social support by role relations: A typology. Social Networks, 28, 427-441. doi:10.1016/j.socnet.2005.10.001

[8] Bernard, M.B., Sim, B.J. and Biggs, S. (2007) Housing and care for older people: Life in an English purposebuilt retirement village. Ageing \& Society, 27, 555-578. doi:10.1017/S0144686X07005983

[9] Decker, A. (2006) Stuck at home: When driving isn't a choice. Access, 29, 28-33.

[10] Collia, D.V., Sharp, J. and Giesbrecht, L. (2003) The 2001 national household travel survey: A look into the travel patterns of older Americans. Journal of Safety Research, 34, 461-470. doi:10.1016/j.jsr.2003.10.001

[11] Alder, G. and Rottunda, S. (2006) Older adults' perspectives on driving cessation. Journal of Aging Studies, 20 , 227-235. doi:10.1016/j.jaging.2005.09.003

[12] Dellinger, A.M., Sehgal, M., Sleet, D.A. and Barrett Connor, E. (2001) Driving cessation: What older former drivers tell us. Journal of the American Geriatrics Society, 49, 431-435. doi:10.1046/j.1532-5415.2001.49087.x

[13] Gray, D., Sahw, J. and Farrington, J. (2006) Community transport, social capital and social exclusion in rural areas. Area, 38, 89-98. doi:10.1111/j.1475-4762.2006.00662.x

[14] Morency, C. (2007) The ambivalence of ridesharing. Transportation, 34, 239-253. doi:10.1007/s11116-006-9101-9

[15] Schönfelder, S. and Axhausen, K.W. (2003) Activity spaces: Measures of social exclusion? Transport Policy, 10, 273286. doi:10.1016/j.tranpol.2003.07.002

[16] Glass, T.A., Mendes de Leon, C.F. and Seeman, T.E. (1997) Beyond single indicators of social networks: A LISREL analysis of social ties among the elderly. Social Science and Medicine, 44, 1503-1517. doi:10.1016/S0277-9536(96)00270-5

[17] Moen, P., Dempster-McClain, D. and Williams, R. (1989) Social integration and longevity: An event history analysis of women's roles and resilience. American sociological Review, 54, 635-647. doi:10.2307/2095884

[18] Miller, H.J. (2003) Travel chances and social exclusion. The 10th International Conference on Travel Behavior Research, Lucerne, 10-14 August 2003.

[19] Roorda, M.J., Paez, A., Morency, C., Mercado, R. and Farber, S. (2010) Trip generation of vulnerable population in three Canadian cities: A spatial ordered probit approach. Transportation, 37, 525-548. doi:10.1007/s11116-010-9263-3

[20] Berkman, L.F., Glass, T., Brissette, I. and Seeman, T.E. (2000) From social integration to health: Durkheim in the new millennium. Social Science and Medicine, 51, 843857. doi:10.1016/S0277-9536(00)00065-4

[21] Cornwell, B. (2011) Age trends in daily social contact patterns. Research on Aging, 33, 598-631. doi:10.1177/0164027511409442

[22] Park, N.S., Jang, Y., Lee, B.S. and Chiriboga, D.A. (2012) 
Racial/ethnic differences in predictors of self-rated health: Findings from the survey of older Floridians. Research on Aging, 34, 1-19.

[23] Cummings, J.L. and Jackson, P.B. (2008) Race, gender, and SES disparities in self-assessed health, 1974-2004. Research on Aging, 30, 137-167. doi: $10.1177 / 0164027507311835$

[24] August, K.J. and Sorkin, D.H. (2010) Racial and ethnic disparities in indicators of physical health status: Do they still exist throughout later life? Journal of American Geriatrics Society, 58, 2009-2015.

doi:10.1111/j.1532-5415.2010.03033.x

PMid:20929470 PMCid:2953730

[25] Michael, Y.L., Berkman, L.F., Colditz, G.A. and Kawachi, I. (2001) Living arrangements, social integration, and change in functional health status. American Journal of Epidemiology, 153, 123-131. doi:10.1093/aje/153.2.123

[26] Vlahov, D., Galea, S. and Freudenberg, N. (2005) The urban health "advantage". Journal of Urban Health: Bulletin of the New York Academy of Medicine, 82, 1-4.

[27] Nakata, A. (2011) Work hours, sleep sufficiency, and prevalence of depression among full-time employees: A community-based cros-sectional study. Journal of Clinical Psychiatry, 72, 605-614. doi:10.4088/JCP.10m06397gry

[28] Fan, Y.L. and Khattak, A.J. (2009) Does urban form matter in solo and joint activity engagement? Landscape and Urban Planning, 92, 199-209. doi:10.1016/j.landurbplan.2009.05.006

[29] Scott, D.M. and Kanaroglou, P.S. (2002) An activityepisode generation model that captures interactions between household heads: Development and empirical analysis. Transportation Research Part B, 36, 875-896. doi:10.1016/S0191-2615(01)00039-X

[30] Kang, H. and Scott, D.M. (2008) An integrated spatiotemporal GIS toolkit for exploring intra-household interactions. Transportation, 35, 253-268. doi:10.1007/s11116-007-9146-4

[31] Kang, H. and Scott, D.M. (2011) Impact of different criteria for identifying intra-household interactions: A case study of household time allocation. Transportation, 38, 81-99. doi:10.1007/s11116-010-9292-y
[32] Gliebe, J.P. and Koppelman, F.S. (2002) A model of joint activity participation between household members. Transportation, 29, 49-72. doi:10.1023/A:1012995509777

[33] Silvis, J. and Niemeier, D.A. (2009) Social network and dwelling characteristics that influence ridesharing behavior of seniors. Transportation Research Record: Journal of the Transportation Research Board, 2118, 47-54.

[34] Fujii, S., Kitamura, R. and Kishizawa, K. (1999) Analysis of individuals' joint-activity engagement using a model system of activity-travel behavior and time use. Transportation Research Record, 1676, 11-19.

[35] Inagami, S., Cohen, D.A. and Finch, B.K. (2007) Nonresidential neighborhood exposures suppress neighborhood effects on self-rated health. Social Science and Medicine, 65, 1779-1791. doi:10.1016/j.socscimed.2007.05.051

[36] Reijneveld, S.A. and Gunning-Schepers, L.J. (1995) Age, health and the measurement of the socio-economic status of individuals. European Journal of Public Health, 5, 187-192. doi:10.1093/eurpub/5.3.187

[37] Svedberg, P., Bardage, C., Sandin, S. and Pedersen, N.L. (2006) A prospective study of health, life-style and psychosocial predictors of self-rated health. European Journal of Epidemiology, 21, 767-776. doi:10.1007/s10654-006-9064-3

[38] Shooshtari, S., Menec, V. and Tate, R. (2007) Comparing predictors of positive and negative self-rated health between younger (25 - 54) and older (55+) Canadian adults: A longitudinal study of well-being. Research on Aging, 29, 512-554. doi:10.1177/0164027507305729

[39] Manor, O., Matthews, S. and Power, C. (2000) Dichotomous or categorical response? International Journal of Epidemiology, 29, 149-157. doi:10.1093/ije/29.1.149

[40] Manderbacka, K., Lahelma, E. and Martikainen, P. (1998) Examining the continuity of self-rated health. International Journal of Epidemiology, 27, 208-213. doi:10.1093/ije/27.2.208

[41] Kang, H. and Scott, D.M. (2010) Exploring day-to-day variability in time use for household members. Transportation Research Part A, 44, 609-619. doi:10.1016/j.tra.2010.04.002 